\title{
Helping Nurses Cope with COVID-19 Pandemic: Evaluating Support Programs
}

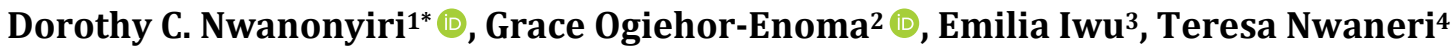 \\ ${ }^{1}$ Felician University, Lodi, New Jersey, USA \\ ${ }^{2}$ Hunter-Bellevue School of Nursing, Hunter College, New York, NY, USA \\ ${ }^{3}$ Rutgers University School of Nursing, Newark, NJ, USA \\ ${ }^{4}$ Seton Hall University, South Orange, NJ, USA \\ Email: *Nwanonyd@kean.edu
}

How to cite this paper: Nwanonyiri, D.C., Ogiehor-Enoma, G., Iwu, E. and Nwaneri, T. (2021) Helping Nurses Cope with COVID-19 Pandemic: Evaluating Support Programs. Open Journal of Nursing, 11, 65-74. https://doi.org/10.4236/ojn.2021.112007

Received: January 7, 2021

Accepted: February 21, 2021

Published: February 24, 2021

Copyright $\odot 2021$ by author(s) and Scientific Research Publishing Inc. This work is licensed under the Creative Commons Attribution International License (CC BY 4.0).

http://creativecommons.org/licenses/by/4.0/

\begin{abstract}
During the height of the Coronavirus Disease (COVID-19) Pandemic, nurses all over the world, including members of the National Association of Nigerian Nurses in North America (NANNNA) experienced a heightened and unprecedented level of stress, anxiety, fear, uncertainty, concern for their safety and that of their loved ones. This prompted NANNNA leadership to initiate and conduct support programs for nurses especially those on the frontline of care. This project evaluates the effectiveness of the support programs conducted by NANNNA during the early surge of COVID-19. The Centers for Disease Control's (CDC's) Framework for Evaluation in Public Health guided this evaluation. Focus group discussion and online survey was utilized to gather data. While $19 \%$ of respondents reported being diagnosed with COVID-19, the majority (81\%) were not. About $44 \%$ of respondents had family members who were diagnosed with COVID-19, while $18 \%$ reported loss of a close family member due to COVID-19 complications. Most respondents reported that the program was impactful in information sharing as well as significant in helping them feel connected with other nurses. Hence, this subsequently enhanced their support networks, provided emotional and spiritual support. Survey results revealed that NANNNA support programs had positive effects in helping members mitigate the fear, anxiety and uncertainty experienced during the surge of the COVID-19.
\end{abstract}

\section{Keywords}

Support Program, Program Evaluation, Nurses, COVID-19

\section{Background}

During the height of the Coronavirus Disease (COVID-19) Pandemic, nurses all 
over the world, including members of the National Association of Nigerian Nurses in North America (NANNNA) experienced unprecedented levels of stress, anxiety, fear, uncertainty, concern for their safety and that of their loved ones. Although stress is part of the nursing profession [1], the COVID-19 pandemic created a heightened level of stress and one that needed immediate intervention. Current literature put forward that some frontline nurses reported having trouble sleeping in addition to fear for personal and family safety [2] [3].

Globally, this prompted many nurses, inclusive of NANNNA members especially those on the front-line of care to consider exiting the nursing profession. Many nurses cited working in high-risk environments without adequate personal protective equipment, working long hours, and lack of support from leadership or management of their institutions as reasons for making this consideration [4].

A survey conducted by the Royal College of Nurses' revealed that $36 \%$ of nurses were considering leaving the profession due to stagnant pay, treatment of nursing staff and low staffing when compared to $27 \%$ in similar report the year prior. According to NBC News, "some front-line nurses have decided to quit their jobs, citing inadequate protection against the novel coronavirus and fear for their safety, along with that of their families". In a recent study, it was evident that there is high concern among nurses for personal and family health during infectious disease outbreaks such as COVID-19 and this was supported by previous studies in an epidemic [5] [6] [7].

According to Slavitt [8], the pandemic actually exposed the shortcomings of the US health care systems, such as lack of accumulation of sufficient personal protective equipment, poor infection control protocols, lack of ability to swiftly and easily share information, shortages in key jobs such as respiratory therapists, nurses and other health practitioners, shaky supply chain of important life-saving medications, inadequate protocol for end-of-life guidance for people dying alone from highly infectious diseases.

This clearly underscored the fact that the healthcare system and nursing workforce were unprepared to deal with the unprecedented challenges imposed by such public health crisis. Particularly in New York city-the epicenter of the US epidemic where the highest rate of infection and deaths was reported, many NANNNA members in the New York City areas and surroundings began to reach out for help, advice and emotional support. This led NANNNA leadership to conduct a rapid assessment through membership survey. This need assessment revealed a need for more in-depth study and programs to support nurses and other healthcare professionals during current and future infectious disease outbreak. Hence, this support program was initiated to address some of those immediate needs.

Providing support for nurses during the surge of the Coronavirus (COVID-19) pandemic aimed at enhancing access to peer and social support as well as providing opportunities to share information that will be helpful in mitigating the 
stressors imposed by the pandemic. Research suggests that supporting nurses during high levels of occupational stress is essential to preserving their health short term and over time [5]. As stated by Dennis [9], support groups offer many advantages in mitigating the psychosocial functioning and health-related quality of life issues imposed by the stressor(s). Additionally, studies have also shown that support groups create opportunities for participants to receive social support and disease-related information [10].

After six months of running the support group that started with one program but expanded to four programs to address the needs of the nurses, NANNNA Research committee implemented a program evaluation to assess the impact. The four programs under evaluation are; 1) Daily Support for Nurses in the frontline of COVID-19 Care; 2) Individual Peer-Support by COVID-19 Survivors; 3) Bereaved Family Support; and 4) Weekly Spiritual Support/Group Prayer. These programs formed a pathway to help nurses feel less stressed, less fearful and less anxious. Evaluating these support programs will help to gather data that will inform current and future support for nurses in similar situations.

\section{Evaluation Design and Methods}

The Centers for Disease Control's (CDC's) Framework for Evaluation in Public Health guided this evaluation (see Figure 1). The framework comprises of six interconnected steps which could be used to design an effective program evaluation. It summarizes and organizes the basic elements of a program evaluation and provides a common structure for conducting an evaluation. The six steps are; 1) Engage stakeholders; 2) Describe the program; 3) Focus the evaluation design; 4) Gather credible evidence; 5) Justify conclusions and 6) Ensure use and share lessons learned [11].

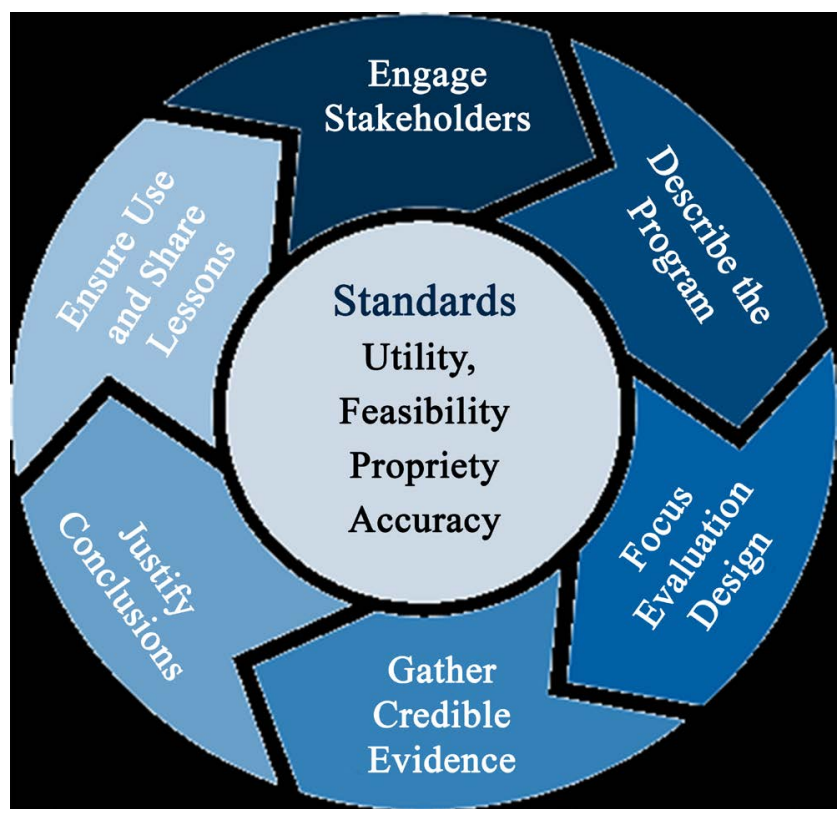

Figure 1. CDC Framework for program evaluation in public health (https://www.cdc.gov/eval/). 
Utilizing this framework as a guide, the major stakeholders, NANNNA Board of Directors (BOD) were invited to participate in a Focus Group Discussion (FGD). The purpose of the FGD was to gather information about the genesis and objectives, plus to understand the phenomenon of interest for initiating the support group from the point of view of the BOD. Essentially, the data from the FGD provided the background for the program evaluation and focus for the evaluation design.

\subsection{Focus Group Discussion (FGD)}

The discussion began with formal introduction of the seven persons NANNNA BOD members and the moderators. This was followed by verbal expression of informed consent and review of conflict-of-interest declaration by each participant. The discussion was conducted virtually through Zoom $^{\circledR}$ video conference platform for approximately one and half hours. Using open-ended questions, the moderators asked participants to share how the support programs originated, the objectives and expected outcomes.

\subsection{How It All Began}

There was a consensus that the support group was initially ran by the organization's Executive Director and supported by other board members during the early stages of running the groups. The Executive Director reported that during the height of COVID-19, she received many calls at different times of the day and night from NANNNA members who were scared and overwhelmed. She shared that some expressed desire to quit their jobs. Those calls led her to believe that there was great anxiety and tension amongst the members. She believed that some level of supportive intervention would help to alleviate the nurses' anxiety. She added:

"This was the genesis for the program because nurses were scared and wanted to quit nursing altogether, I thought to myself that I need to start a support group. At first, the thought was to run a support group for New York NANNNA members since they were seeing the largest cases in the country".

But, she quickly realized the importance of expanding it to all NANNNA members as other states were seeing increasing cases of the COVID-19 as well. Knowing that the process will be very challenging and overwhelming to handle alone, she reached out to the board members to assist.

\subsection{Implementing the Program}

The participants reported that they initially thought about creating a hotline for nurses to call in but later decided to use the organization's existing teleconference line. Information about the support programs were disseminated through the group's social media. Attendance was open to every nurse regardless of his or her membership to NANNNA. Initially the support group ran daily for two 
hours (from $6 \mathrm{pm}$ to $8 \mathrm{pm}$ Eastern US time). The participants reported that more nurses called in the last hour than in the first hour. As a result, the timing was decreased to one hour daily from $7 \mathrm{pm}$ to 8 pm Eastern US time.

According to the participants, turnout was robust for the first 3 - 4 months but gradually decreased as availability of PPEs improved and nurses were becoming more knowledgeable about dealing with the challenges imposed by COVID-19 pandemic. This prompted a reassessment of the program and subsequent adjustment in the frequency and eventual reduction from daily to twice weekly on Tuesday and Thursday from $7 \mathrm{pm}$ to $8 \mathrm{pm}$ Eastern US time.

In terms of structure for the group sessions, one of the participants who is a global nurse expert shared; "we borrowed from experiences with running support groups for nurses caring for patients living with Human Immunodeficiency Virus and Acquired Immunodeficiency Syndrome (HIV \& AIDS) in the early years. "There were lots of similarities with what is happening now with nurses being afraid, this mirrored what we witnessed in HIV care". Using that structure, facilitators guided nurses to share their experiences in the frontline, helped them to identify their strength, discuss updates about COVID-19, dialogue about challenges and brainstorm about possible solutions, etc.

The main reason the support group was created for members of NANNNA was because these nurse leaders are knowledgeable about the cultural uniqueness of the group and were more sensitive to the groups' needs. As Nigerians, they also were comfortable navigating the cultural or religious nuances during the sessions. They also stated that the support group later diversified to enhance support for members who were infected with COVID-19 and others who were bereaved. As is unique with the Nigerian community, some of these nurses did not want to disclose these personal or family situations publicly during the group sessions. This led to the creation of more individualized support to ensure their needs were met.

On another note, the FGD revealed that the participants also benefited from the support program. One participant shared; "I was taking information gathered from the support group to inform my current practice" Another participant (a retired Public Health practitioner) shared; "as a retired nurse, participating in the support group helped me to stay up-to-date with current and evidence-based practices instead of relying on what I hear on television" This participant further shared; "I didn't just learn from it, I used it to educate others in my inner circle and community." Another participant described how she utilized the information obtained from the support program to help develop capacity of an international organization's COVID-19 taskforce. One participant was able to educate her church members using the coping strategies she learned from the support group.

\subsection{Objectives of the Support Group}

As reported by the BOD, the main idea behind the initiation of the support was to give members the opportunities to share their experiences with a larger au- 
dience instead of just sharing it with the executive director alone. The other group objectives were:

1) Reduce the anxiety of nurses on the frontline

2) Preserve nurses' health and minimize the chances of infection.

3) Educate nurses about available resources in their facilities.

4) Teach members on how to develop plans to protect family members in the event of exposure.

5) Teach members on how to provide support for their family when isolating at home.

6) Promote mental wellness and resilience.

\subsection{Data Collection through Survey}

A questionnaire was developed by NANNNA Research committee members to gather credible evidence to determine whether the objectives of the support programs were met. Using an online Survey Monkey platform, the questionnaire distributed through the association's WhatsApp's groups, Emails and Website. The survey opened from August $10^{\text {th }}$ to $31^{\text {st }}, 2020$ and took approximately fifteen (15) minutes for completion. Participation was strictly voluntary and no identifying information was collected.

\section{Survey Findings}

A total of fifty-three nurses responded to the survey, female $(\mathrm{n}=50 ; 94 \%)$ and male $(\mathrm{n}=3 ; 5 \%)$. Of those who responded, $94 \%$ were members of NANNNA while $6 \%$ were non- NANNNA members. In terms of which support programs nurses participated in, there were forty-eight respondents. Most nurses $(n=41$; 85\%) participated in the Daily Support Group for Nurses in the frontline of COVID-19 care; $(\mathrm{n}=25 ; 52 \%)$ participated in the Weekly Spiritual Support/Group Prayer; $(\mathrm{n}=11 ; 23 \%)$ participated in the Individual Peer-Support by COVID-19 Survivors, while $(\mathrm{n}=8 ; 17 \%)$ participated in the Bereaved Family Support (see Figure 2).

Responding to the reason(s) for participating in the support groups, most respondents; $(76 \%)$ indicated that they wanted to learn how other nurses were dealing with the pandemic in their facilities. Next were seeking self-support (73\%) and gaining more knowledge about COVID-19 (67\%). About one third of respondents (41\%) reported that providing support for family member(s) and offering support to other nurses were their reasons for participating in the support group (see Figure 3). Most respondents participated in the programs $1-2$ times per week.

While $19 \%$ of respondents reported personal diagnosis with the COVID-19, the majority (81\%) were not infected. About $44 \%$ of the nurses reported having family members who became infected with COVID-19 while $18 \%$ lost a loved one to complications of COVID-19. Overall, $86 \%$ of respondents reported that 


\section{Which Support program did you attend?}

(Please, check all that apply)

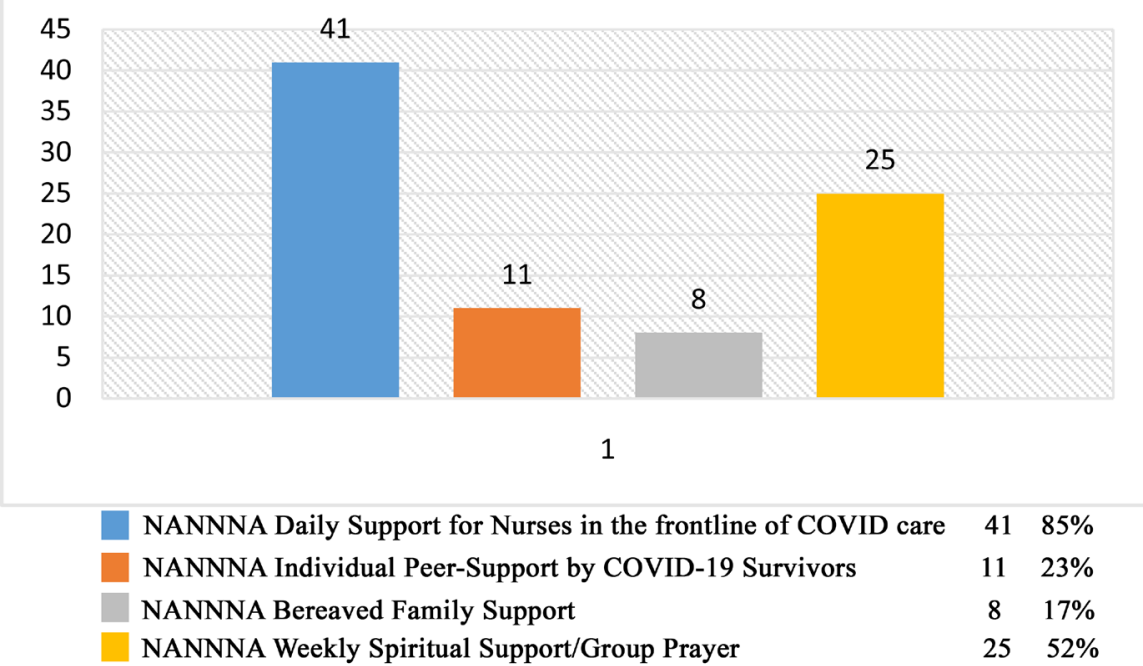

Figure 2. Types of support programs.

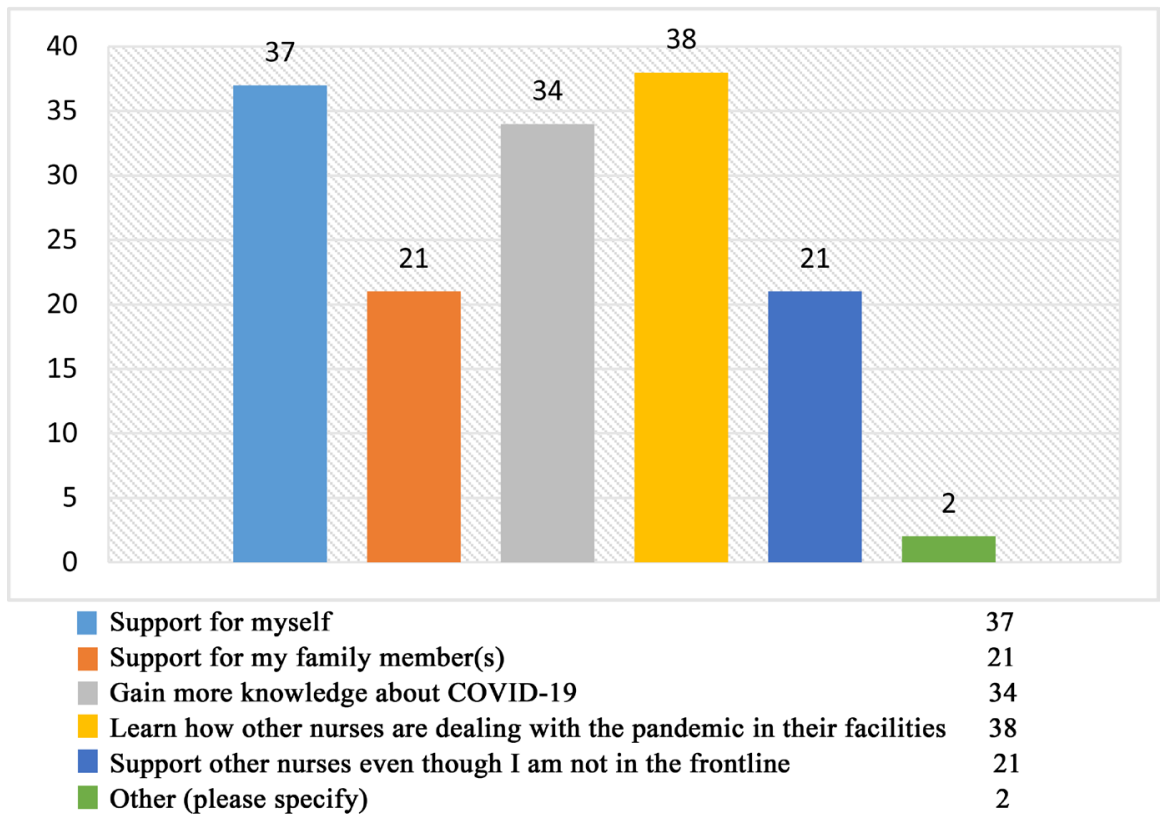

Figure 3. Reasons for participating in support programs.

the program was very helpful in sharing beneficial information and best practices, while $67 \%$ reported feeling connected. About $71 \%$ of the nurses reported that the program helped them with emotional support and spiritual support was reported by $61 \%$ of nurses.

As a result of participating in the support program(s), most of the respondents reported feeling supported by the organization (64\%). Some; $46 \%$ of nurses reported that they were able to recognize their limits when caring for COVID-19 positive patients, practiced self-reflection, self-compassion, and 
self-care. Others; $62 \%$ reported that they were able to share COVID-19 related feelings and experiences with colleagues and while $46 \%$ reported that they were able to spend quality time with their loved ones.

Respondents also shared that because they participated in the support programs, they gained knowledge about current treatment/management modalities for COVID positive patients and became more assertive in requesting for adequate PPE. Survey respondents further shared that hearing from other COVID-19 survivors was helpful in their recovery. Some respondents indicated that they experienced spiritual healing, coped better with the anxiety of returning to work after COVID-19 exposure and as well as engaged in journaling. About $12 \%$ of respondents indicated that the support programs helped them to cope better with the grief of losing a loved one.

In response to a qualitative feedback for the program improvements, the participants proffered the following recommendations, 1) decentralization of the group by creating Regional groups. This would enhance personal connection and support, 2) creating improved awareness about the program at the local levels to encourage participation, 3 ) encouraging participants to allow fair hearing from everybody without interruption, 4) Inclusion of inter-professional colleagues and 5) Developing a structured outline on how to run a support group as an output from the program.

\section{Discussion of Findings}

The purpose of this project was to evaluate the effectiveness of support programs conducted by NANNNA for its members especially those on the frontline of care in the battle against COVID-19. Looking at the objectives as described by the stakeholders, the survey result indicates that the support programs had a beneficial effect on the participants. The support programs were also effective in reducing fear, anxiety by educating nurses through information sharing. The respondents indicated several reasons for participating in the programs which includes but not limited to learning from other nurses, supporting themselves and gaining more knowledge about COVID-19.

In terms of what the participants found most useful about NANNNA Support program, the survey result showed that the goal as stipulated by the stakeholders was met in areas of providing support and education. However, the support program survey findings were limited to the responses provided by members of NANNNA who participated in the survey. This may not be generalizable to other nurses. Therefore, it would be important to look at support programs involving a wider array of nurses in different groups. During the FGD, the interviewers may have unintentionally influenced how participants responded to questions asked.

\section{Conclusions}

Like many other health professional organizations, the leadership of NANNNA 
implemented support programs to educate and address the psychosocial needs of its members at the onset of COVID-19 pandemic. The support program was a very timely and beneficial intervention for NANNNA members and nurses in general. Cultural awareness also played an important role in helping to tailor the support intervention to address the needs of Nigerian nurses who became infected but did not feel comfortable to openly share their experiences. Therefore, it was vital that these nurses were given the opportunity to share information with nurses who had similar experiences. NANNNA modeled in real time, provision of a critical aspect of health equity. Members who were bereaved were identified and provided a social space and needed support as they mourned their loved ones.

Participation in the support program helped respondents cope better with the challenges imposed by COVID-19. Overall, NANNNA support programs had positive effects of helping members mitigate the fear, anxiety and uncertainty experienced during the surge of the COVID-19. Hopefully, these findings from this program evaluation identified areas to inform policies and programs that will support frontline workers and reform the availability of PPEs in future disease outbreaks. This project also supports the importance of utilizing support programs during times of stressful life events as an effective way of reducing affected individuals' fear, anxiety and help people develop better coping mechanisms.

\section{Acknowledgements}

We would like to express our sincere gratitude to our colleagues: Dr. Ola Aloba, Christie, Ndumele, Idorenyi Udosen, Stella Ekeocha Anele, Dr. Josephine, Ezemobi, \& Dr. Ruth, Ifediora for assisting in developing the survey questions. We would also like to extend our heartfelt gratitude to Dr. Andrew Awoniyi for disseminating the survey question and Dr. Agatha Eke for moderating the focus group discussion. Our special thanks also go to the Board of Directors for participating in the FGD. Most importantly, we would like to thank the Almighty God for protecting all NANNNA members, especially those on the frontline as they battled this wicked enemy-COVID-19.

\section{Conflicts of Interest}

The authors declare no conflicts of interest regarding the publication of this paper.

\section{References}

[1] Najimi, A., Goudarzi, A.M. and Sharifirad, G. (2012) Causes of Job Stress in Nurses: A Cross-Sectional Study. Iranian Journal of Nursing and Midwifery Research, 17, 301.

[2] Pappa, S., Ntella, V., Giannakas, T., Giannakoulis, V.G., Papoutsi, E. and Katsaounou, P. (2020) Prevalence of Depression, Anxiety, and Insomnia among Healthcare Workers during the COVID-19 Pandemic: A Systematic Review and Meta-Analysis. 
Brain, Behavior, and Immunity. https://doi.org/10.2139/ssrn.3594632

[3] Fernandez, R., Lord, H., Halcomb, E., Moxham, L., Middleton, R., Alananzeh, I. and Ellwood, L. (2020) Implications for COVID-19: A Systematic Review of Nurses' Experiences of Working in Acute Care Hospital Settings during a Respiratory Pandemic. International Journal of Nursing Studies, 111, Article ID: 103637. https://doi.org/10.1016/j.ijnurstu.2020.103637

[4] Bagnasco, A., Zanini, M., Hayter, M., Catania, G. and Sasso, L. (2020) COVID 19-A Message from Italy to the Global Nursing Community. Journal of Advanced Nursing. Centers for Disease Control and Prevention: http://www.cdc.gov/eval/ https://doi.org/10.1111/jan.14407

[5] Maben, J. and Bridges, J. (2020) COVID-19: Supporting Nurses' Psychological and Mental Health. Journal of Clinical Nursing, 29, 2742-2750.

https://doi.org/10.1111/jocn.15307

[6] Jiang, Y. (2020) Psychological Impact and Coping Strategies of Frontline Medical Staff in Hunan between January and March 2020 during the Outbreak of Coronavirus Disease 2019 (COVID-19) in Hubei, China. Medical Science Monitor, 26, e924171. https://doi.org/10.12659/MSM.924171

[7] Khalid, I., Khalid, T.J., Qabajah, M.R., Barnard, A.G. and Qushmaq, I.A. (2016) Healthcare Workers Emotions, Perceived Stressors and Coping Strategies during a MERS-CoV Outbreak. Clinical Medicine \& Research, 14, 7-14. https://doi.org/10.3121/cmr.2016.1303

[8] Slavitt, A. (2020) The COVID-19 Pandemic Underscores the Need to Address Structural Challenges of the US Health Care System. In JAMA Health Forum (Vol. 1, No. 7, pp. e200839-e200839). American Medical Association.

https://www.beckershospitalreview.com/nursing/nurses-say-changing-guidelines-u nsafe-conditions-are-pushing-them-to-quit.html https://doi.org/10.1001/jamahealthforum.2020.0839

[9] Dennis, C.L. (2003) Peer Support within a Health Care Context: A Concept Analysis. International Journal of Nursing Studies, 40, 321-332. https://doi.org/10.1016/S0020-7489(02)00092-5

[10] Pépin, M., Kwakkenbos, L., Carrier, M.E., Peláez, S., El-Baalbaki, G., Malcarne, V. L., et al., Scleroderma Patient-Centered Intervention Network (SPIN) Support Group Project Advisory Team. (2019). Reasons for Attending Support Groups and Organizational Preferences: A Replication Study Using the North American Scleroderma Support Group Survey. Journal of Scleroderma and Related Disorders, 4, 173-186. https://doi.org/10.1177/2397198319849806

[11] Centers for Disease Control's (CDC's) Framework for Evaluation in Public Health Guided this Evaluation. http://www.cdc.gov/eval 